\title{
Pengembangan dan Implementasi dari Wise Netizen (E- Comment) di Indonesia
}

\author{
The Development And Implementation Of Wise Netizen (E-Comment) In Indonesia
}

\author{
Indra Gamayanto ${ }^{* 1}$, Florentina Esti Nilawati ${ }^{2}$, Suharnawi ${ }^{3}$ \\ Program Studi Sistem Informasi, Universitas Dian Nuswantoro, Semarang \\ e-mail: *11indra.gamayanto@dsn.dinus.ac.id, ${ }^{2}$ nilawatiflorentina@gmail.com, ${ }^{3}$ nawigr@gmail.com
}

\begin{abstract}
Abstrak
Sosial Media merupakan salah satu pilar penting di dalam teknologi informasi, dimana sosial media dapat digunakan untuk menghasilkan sesuatu yang positif dan negative, sosial media juga dapat digunakan untuk memberikan komentar-komentar baik itu yang bersifat membangun secara positif atau menjatuhkan secara negative, dan terakhir sosial media dapat juga membuat seseorang mengalami hal-hal buruk akibat apa yang telah dilakukan oleh orang lain di dalam sosial media. Di dalam Jurnal ini, menciptakan "Netizen Development Methodology" yang memiliki manfaat untuk memberikan petunjuk positif terhadap para pengguna sosial media agar lebih positif dalam menggunakan media tersebut. Facebook dan Twitter, menjadi dua sosial media yang menjadi focus, di dalam jurnal ini tidak menggantikan apa yang sudah ada, tidak mengkritik para netizen dan juga tidak memberikan pendapat-pendapat negative tentang hal-hal yang sudah dilakukan oleh orang lain. Penelitian ini berusaha memberikan apa yang telah diciptakan agar digunakan sebagai masukkan terhadap para pengguna sosial media khususnya di Indonesia agar dapat menjadi lebih positif, agar menghasilkan solusi-solusi kreatif yang dapat membantu satu sama lain, sehingga dapat tercipta kedamaian dan kesatuan antar para pengguna sosial media.
\end{abstract}

Kata Kunci: Netizen, Sosial media, Moralitas, Etika, Sistem Informasi Manajemen, Hate Speech, Networking

\begin{abstract}
Social media is one of the important pillars in information technology, in which social media can be used to produce something that is positive and negative, social media can also be used to provide comments either constructive positively or bad comment, negatively, and lastly sosial media can also make a person experiences bad things as a result of what has been done by others in the social media. In the journal, it will develop a Netizen Development Methodology that has positive benefits to give instructions to the users of social media to be more positive in using media. Facebook and Twitter are the focus; this journal does not replace what already exists, not criticize netizens and also does not give the negative opinions about things that have been done by others. This research seeks to provide what has been created to be used as an insert to the users of sosial media, especially in Indonesia in order to become more positive, in order to produce creative solutions that can help each other, so as to create peace and unity among users of sosial media.
\end{abstract}

Keywords: Netizen, Social media, Morality, Ethics, Management Information Systems, Hate Speech, Networking

\section{PENDAHULUAN}

Perkembangan teknologi informasi sedemikian pesatnya di Indonesia, sehingga seharusnya dapat mengimbanginya dengan mengembangkan kemampuan karena pada zaman globalisasi dan 
Masyarakat Ekonomi Asean (MEA), kemampuan sangatlah penting untuk diperhatikan, menyaring informasi juga sangat diperlukan karena banyak informasi yang berseliweran dan di sini dibutuhkan kehati-hatian dalam memilihnya, membaca dan mempelajarinya. Lebih jauh lagi Sosial media merupakan "senjata", alat dan juga sarana untuk menyebarkan informasi, berpendapat, sharing, mengekspos diri secara berlebihan (narcissism) dan masih banyak lagi. Pada penelitian ini akan mengangkat topic yang berhubungan dengan sosial media dan netizen, mengapa? Karena banyak sekali sekarang peraturan yang dibuat dan masyarakat seakan akan kebingungan, patokan mana yang akan digunakan?, apa batasannya? Dan masih banyak pertanyaan yang diajukan oleh kita pada umumnya. Penelitian ini akan mencoba untuk memberikan sebuah framework guna membantu para pengguna sosial media untuk dapat memberikan pendapatnya dengan cara yang cerdas, bijaksana, sesuai dengan moral dan etika (yang pada saat ini sering digaungkan). Maka, dengan ini, kami akan memulainya dengan beberapa definisi penting, yang kami quotes dari beberapa sumber: Pertama, kita akan mendefinisikan arti dari Netizen. "MAKNA, arti, definisi, atau pengertian Netizen secara harfiyah adalah "warga internet". Istilah NETIZEN dibentuk dari dua kata: INTERNET dan CITIZEN (warga). Jadi, bisa disimpulkan, Netizen adalah user (pengguna) internet aktif dalam berkomunikasi, mengeluarkan pendapat, berkolaborasi, di media internet.[11];[12];[13];[14];[15] Facebook aktif, blogger, pengguna twitter (tweeps), dan "aktivis" sosial media lainnya termasuk dalam kategori netizens. Jika seorang user hanya sesekali membuka internet, misalnya untuk mengirim dan menerima/membaca email, belum bisa disebut Netizen. Muncul juga istilah lain dari Netizen ini, yakni Netizen Journalism (Jurnalitik Warga Internet), yaitu aktivitas penulisan dan penyebarluasan berita atau informasi aktual melalui internet --blog, media sosial, dan sebagainya. Namun, saat ini Netizen Journalism baru sebatas "share and comments" terhadap berita-berita yang sudah ada, misalnya koreksi, kritik, pujian, rekomendasi ke teman. Netizen Journalism bahkan bisa berperan sebagai "Watchdog Journalism" --mengawasi dan mengkritisi apa saja, bahkan mengkritisi berita yang dibuat oleh para wartawan professional [5];[6]. Dari definisi ini, kita mengetahui bahwa di Indonesia masih terdapat tantangan yang besar terhadap hal-hal tersebut. kita melihat terkadang banyak terjadi komentar dan sebagainya yang masih mungkin beberapa kalangan menyebutnya "kurang etis" dan lain-lain. Dalam penelitian ini, akan menghadirkan framework yang mungkin bisa digunakan untuk mengatasi hal tersebut. Data di bawah ini akan sangat membantu kita untuk dapat memahami lebih dalam bagaimana cara menggunakan sosial media secara bijaksana, dan data di bawah ini merupakan dasar daripada penelitian ini Indonesia, data yang diperoleh dari Sophie Loras, Asia Insights Social Sosial media, Sosial media in Indonesia: big numbers with plenty of room to grow, dan Judith Balea, The latest stats in web and mobile in Indonesia (Infographic): [20]; [31]

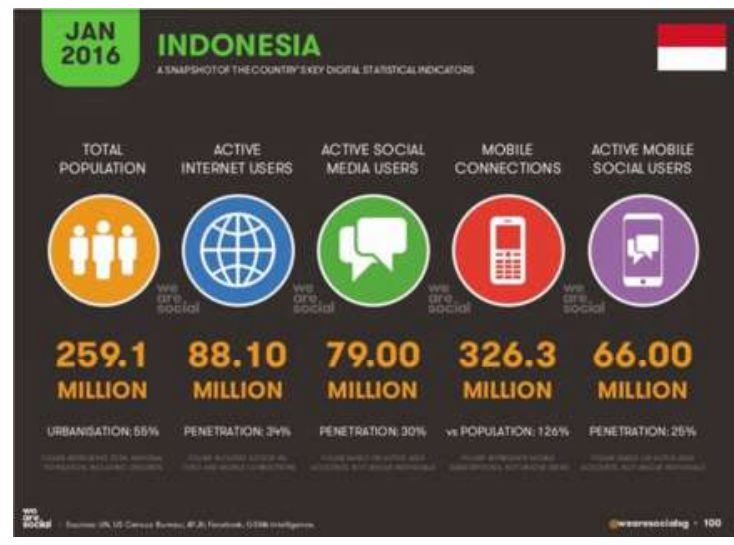

Gambar 1. Pengguna Digital Di Indonesia 
Pada gambar 1 yang dikemukakan oleh Judith Balea, dapat dilihat populasi penduduk di Indonesia hampir mencapai 260 juta, dengan pengguna aktif mencapai 88.10 juta, serta pengguna aktif sosial media 79.00 merupakan tantangan besar untuk Indonesia dalam menciptakan netizen yang bijaksana. Pada gambar 2, dapat dilihat data berikutnya dapat dilihat bahwa pengguna Facebook nomer 2 terbanyak setelah BBM, dan Twitter menempati urutan ke 7, jumlahnya akan terus meningkat seiiring dengan perkembangan sosial media di dunia

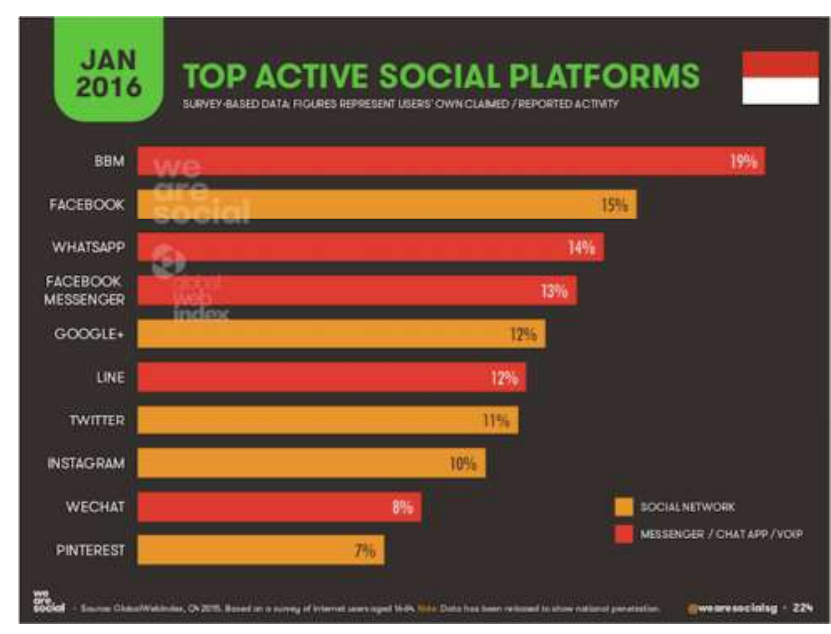

Gambar 2. Top Active pengguna Social Platform

Data berikutnya yang dihadirkan adalah dari tahun 2013 hingga perkiraan peningkatan pengguna sampai pada tahun 2019. Dapat dilihat dari data yang ada bahwa angkanya terus melonjak naik, sehingga Indonesia membutuhkan peraturan penggunaan sosial media secara bijaksana.

\begin{tabular}{|c|c|c|c|c|c|c|c|}
\hline \multicolumn{8}{|c|}{$\begin{array}{l}\text { Social Network Users and Penetration in Indonesia, } \\
\text { 2013-2019 }\end{array}$} \\
\hline & 2013 & 2014 & 2015 & 2016 & 2017 & 2018 & 2019 \\
\hline $\begin{array}{l}\text { Social network } \\
\text { users (millions) }\end{array}$ & 55.9 & 64.5 & 72.3 & 82.0 & 92.1 & 100.8 & 109.8 \\
\hline - $\%$ change & $29.9 \%$ & $15.4 \%$ & $12.1 \%$ & $13.5 \%$ & $12.3 \%$ & $9.4 \%$ & $8.9 \%$ \\
\hline - $\%$ of internet users & $76.7 \%$ & $77.0 \%$ & $77.4 \%$ & $79.8 \%$ & $81.9 \%$ & $82.0 \%$ & $82.2 \%$ \\
\hline —\% of population & $22.3 \%$ & $25.4 \%$ & $28.2 \%$ & $31.8 \%$ & $35.4 \%$ & $38.4 \%$ & $41.4 \%$ \\
\hline \multicolumn{8}{|c|}{$\begin{array}{l}\text { Note: internet users who use a social network via any device at least once } \\
\text { per month } \\
\text { Source: eMarketer, Dec 2014; confirmed and republished, July } 2015\end{array}$} \\
\hline
\end{tabular}

Gambar 3. Social Network User, Indonesia

Data berikutnya menghadirkan para pengguna Facebook yang meningkat drastis tahun demi tahun, data ini juga meliputi para pengguna Twitter sampai pada tahun 2019: 
Facebook Users and Penetration in Select Countries in Southeast Asia, 2014-2019

millions and \% of internet users

\begin{tabular}{|c|c|c|c|c|c|c|}
\hline & 2014 & 2015 & 2016 & 2017 & 2018 & 2019 \\
\hline \multicolumn{7}{|c|}{ Facebook users (millions) } \\
\hline Indonesia & 58.5 & 67.7 & 77.7 & 87.8 & 96.3 & 105.1 \\
\hline Philippines & 31.8 & 37.2 & 42.1 & 46.6 & 50.4 & 54.0 \\
\hline Vietnam & 25.6 & 29.4 & 32.7 & 36.0 & 39.0 & 41.9 \\
\hline Thailand & 15.6 & 17.3 & 18.9 & 20.3 & 21.5 & 22.7 \\
\hline Malaysia & 8.9 & 9.8 & 10.6 & 11.5 & 12.4 & 13.2 \\
\hline Singapore & 2.7 & 2.9 & 3.0 & 3.2 & 3.3 & 3.4 \\
\hline
\end{tabular}

Facebook user penetration (\% of internet users)

\begin{tabular}{lllllll}
\hline Indonesia & $69.9 \%$ & $72.5 \%$ & $75.6 \%$ & $78.0 \%$ & $78.3 \%$ & $78.7 \%$ \\
\hline
\end{tabular}

\begin{tabular}{lllllll}
\hline Philippines & $66.1 \%$ & $69.2 \%$ & $71.3 \%$ & $72.3 \%$ & $72.7 \%$ & $73.0 \%$ \\
\hline
\end{tabular}

\begin{tabular}{lllllll}
\hline Malaysia & $65.3 \%$ & $68.0 \%$ & $69.7 \%$ & $70.7 \%$ & $71.3 \%$ & $71.8 \%$ \\
\hline
\end{tabular}

\begin{tabular}{lllllll}
\hline Singapore & $64.5 \%$ & $67.4 \%$ & $69.0 \%$ & $70.1 \%$ & $70.8 \%$ & $71.3 \%$ \\
\hline
\end{tabular}

\begin{tabular}{lllllll}
\hline Thailand & $64.0 \%$ & $66.8 \%$ & $68.5 \%$ & $69.7 \%$ & $70.4 \%$ & $70.9 \%$ \\
\hline
\end{tabular}

\begin{tabular}{lllllll}
\hline Vietnam & $63.4 \%$ & $66.2 \%$ & $67.9 \%$ & $69.1 \%$ & $69.8 \%$ & $70.3 \%$ \\
\hline
\end{tabular}

Note: internet users who access their Facebook account via any device at least once per month

Source: eMarketer, Nov 2015

Gambar 4. Facebook Users

Twitter Users and Penetration in Select Countries in

Southeast Asia, 2014-2019

millions and \% of internet users

\begin{tabular}{lrrrrrr}
\hline & $\mathbf{2 0 1 4}$ & $\mathbf{2 0 1 5}$ & $\mathbf{2 0 1 6}$ & $\mathbf{2 0 1 7}$ & $\mathbf{2 0 1 8}$ & $\mathbf{2 0 1 9}$ \\
\hline \multicolumn{2}{l}{ Twitter users (millions) } & & & & & \\
\hline Indonesia & 12.0 & 14.3 & 16.8 & 18.9 & 20.9 & 22.8 \\
\hline Philippines & 5.5 & 6.6 & 7.5 & 8.5 & 9.5 & 10.4 \\
\hline Vietnam & 4.0 & 4.7 & 5.4 & 6.1 & 6.7 & 7.3 \\
\hline Thailand & 2.7 & 3.1 & 3.4 & 3.7 & 3.9 & 4.1 \\
\hline Malaysia & 1.5 & 1.7 & 1.9 & 2.1 & 2.2 & 2.4 \\
\hline Singapore & 0.4 & 0.4 & 0.5 & 0.5 & 0.5 & 0.6 \\
\hline
\end{tabular}

Twitter user penetration ( $\%$ of internet users)

\begin{tabular}{lllllll}
\hline Indonesia & $14.3 \%$ & $15.4 \%$ & $16.3 \%$ & $16.8 \%$ & $17.0 \%$ & $17.1 \%$ \\
\hline Philippines & $11.4 \%$ & $12.2 \%$ & $12.8 \%$ & $13.2 \%$ & $13.7 \%$ & $14.1 \%$ \\
\hline Malaysia & $11.1 \%$ & $11.9 \%$ & $12.4 \%$ & $12.7 \%$ & $12.8 \%$ & $12.9 \%$ \\
\hline Thailand & $11.0 \%$ & $11.8 \%$ & $12.3 \%$ & $12.6 \%$ & $12.8 \%$ & $12.9 \%$ \\
\hline Vietnam & $9.8 \%$ & $10.5 \%$ & $11.1 \%$ & $11.6 \%$ & $12.1 \%$ & $12.2 \%$ \\
\hline Singapore & $9.2 \%$ & $10.3 \%$ & $10.8 \%$ & $11.3 \%$ & $11.7 \%$ & $12.1 \%$
\end{tabular}

Note: internet users who access their Twitter account via any device at

Source: eMarketer, Nov 2015

Gambar 5. Twitter Users 


\section{METODE PENELITIAN}

\section{II.1 Sosial media: Faktor Manusia; Nilai Sebuah Teknologi Informasi Dan Etika}

Jika berbicara tentang sosial media maka akan banyak menemukan hal-hal yang menarik dan bahkan yang menjengkelkan, sebab di dalam sosial media, terkadang terdapat perkataan 'bablas' dalam memposting sesuatu; mengatakan/berkomentar sesuatu; dan mungkin masih banyak hal-hal lainnya yang perlu menjadi bahan pertimbangan sebelum melakukannya. Ingat dengan "Hate Speech" yang telah dikeluarkan oleh Kepolisian Republik Indonesia, dalam hal ini masyarakat sepenuhnya mendukung dan sangat setuju, karena di sini diperlukan sebuah panduan yang berlandaskan hukum sehingga tidak lagi "bablas" atau "keterlaluan" dalam berperilaku di sosial media. Apakah memang diperlukan? Jawabannya adalah: "Dengan budaya yang kita miliki sekarang, sangat-sangat dan sangat diperlukan". [17]. Mari memulainya dengan memahami apa yang disebut dengan sosial media? Sosial media dibangun untuk berkomunikasi satu sama dengan tujuan utamanya adalah berbagi satu sama lain, dengan kata lain komunikasi dua arah, jika kita dapat memahami hal ini maka penggunaan social media akan dapat sangat menguntungkan bagi pengguna" [20]. Hal tersebut dapat digambarkan dengan gambar berikut ini:

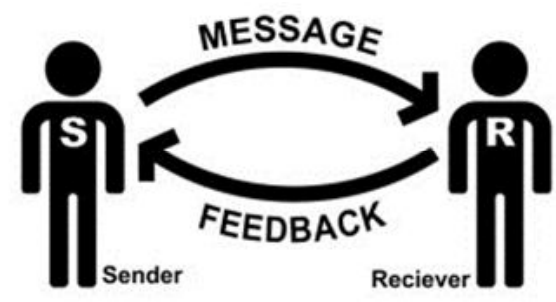

Gambar 6. Sender-Receiver-Communication [20]

Setelah kita memahami definisi sosial media, maka kita perlu juga memahami bahwa banyak sekali sosial media yang ada sekarang, dan ini menjadi suatu concern yang sangat tinggi dan sekaligus tantangan bagi kita untuk dapat memberikan edukasi kepada budaya kita, untuk mengubah orang-orang agar dapat lebih Smart dalam mengemukakannya apa yang terdapat di dalam pikirannya agar dapat tercipta sebuah situasi dan kondisi yang positif.[21];[22]. Dalam penelitian ini hanya akan berfokus pada dua sosial media yang sangat dikenal, yaitu Facebook dan Twitter. Frameworknya adalah sebagai berikut:

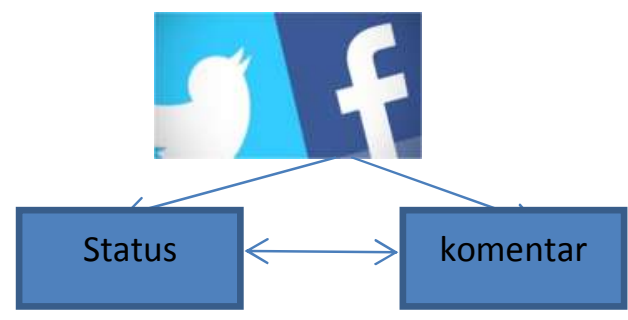

Gambar 7. Facebook-Twiteer-Status-Komentar [22] 
Dua hal yang menjadi pusat, yaitu status dan komentar. Berfokus pada apa yang disebut "komentar" karena ini merupakan salah satu inti permasalahan yang sering terjadi. Komentar yang baik dan sopan, komentar yang "pedas", komentar yang mengandung unsur-unsur negatif, dan masih banyak lagi. Apakah kita bisa mengubah hal ini?, di sini terdapat beberapa pengertian yang harus dipahami, antara lain: Daniel Goleman, $\mathrm{PhD}$ mengatakan bahwa telpon genggam dan social media memperluas wawasan kita dengan orang lain dan di sini proses pengumpulan informasi dapat jauh lebih cepat dan lebih mudah daripada sebelumnya. Lebih jauh lagi, Nicola Formichetti mengatakan, Terdapat sisi gelap dalam social media, dimana dalam hitungan detik saja hal-hal yang terdapat di dalam social media akan dapat diambil di luar konteks dan proporsi yang seharusnya. Dan terakhir, Amy Jo Martin mengatakan, Sosial media mengubah cara kita berkomuniasi baik secara positif maupun negatif, setiap kali dilakukan pengubahan status, mengirim foto, akan terdapat kontribusi jejak pribadi di dalamnya.[3];[4]. Melihat definisi-definisi tersebut, maka dapat dipahami sosial media yang dihubungkan dengan Moral dan Etika sebagai berikut:

1. Setiap manusia tidak dapat dilepaskan dari budaya dan lingkungan yang mempengaruhinya. Dan hal ini menghasilkan sikap pada dirinya.

2. Setiap manusia memiliki hati nurani yang seharusnya dapat menjadi pengingat agar reaksi-reaksi yang dikeluarkannya tidak menimbulkan sebuah kegaduhan, yang membuat lingkungan menjadi tidak nyaman. Di sini terdapat perbedaan antara "kegaduhan untuk menjadikan sebuah situasi positif" atau "kegaduhan yang sekedar mencari sensasi dan menjadikan dirinya pusat perhatian [Narsistik]".

3. Setiap manusia tidak boleh melepaskan dasar moral dan etika yang baik, yang terdapat di dalam dirinya. Di sini harus dapat memahami apa artinya "membenci secara dewasa dan membenci secara bodoh".

Oleh sebab itu, tingkat kedewasan seseorang terkadang bisa diukur daripada apa yang ia katakan di sosial media atau apa yang dilakukannya di sosial media. Di sini diciptakan sebuah kerangka dalam melakukan penelitian:

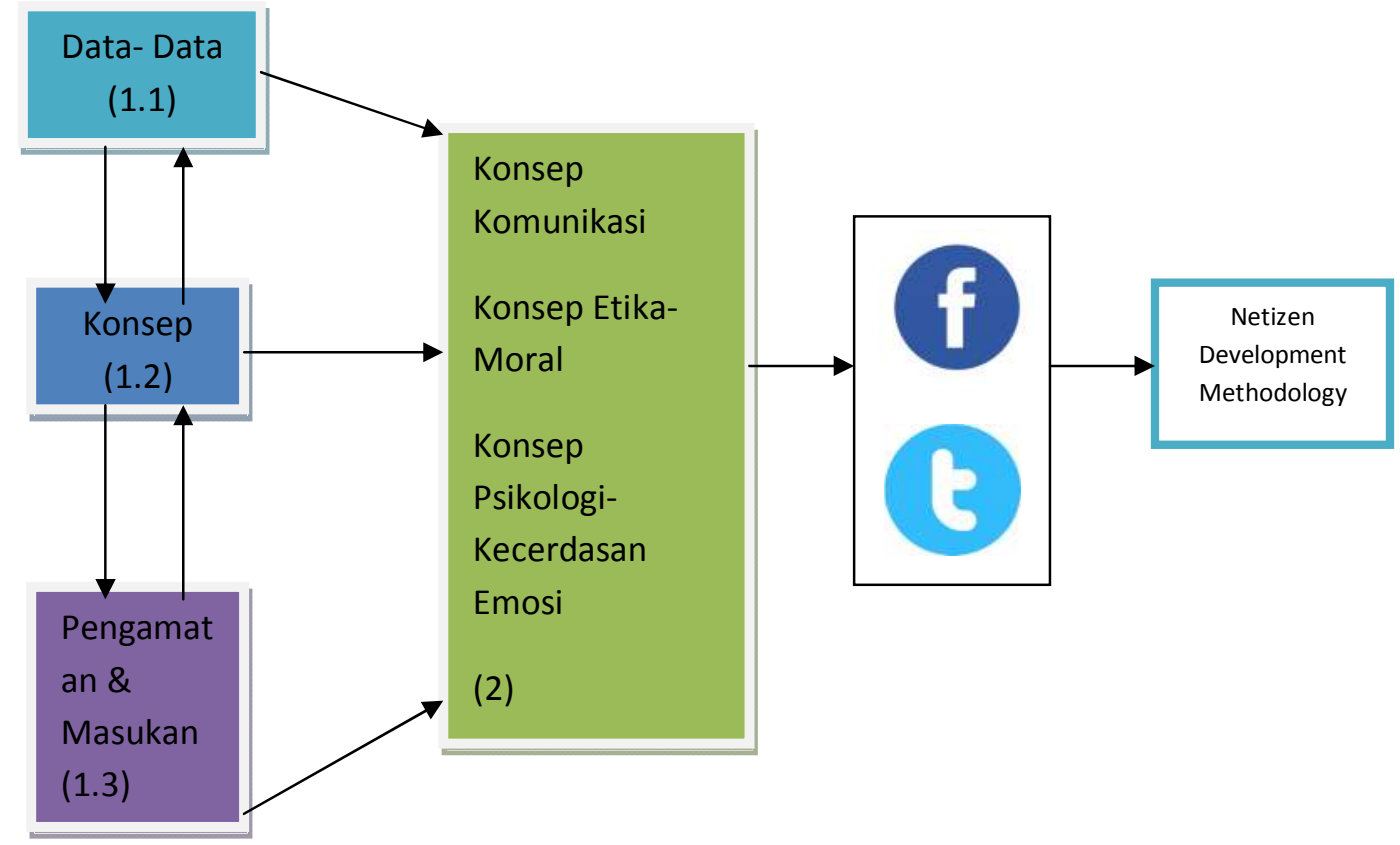

Gambar 8. Proses Merancang \& Membangun Netizen Development Methodology 


\section{II.2. Komentar Dalam Sosial Media \& Membentuk Integritas Netizen}

Apa yang menjadi akar dari pertengkaran atau perselisihan? Kebanyakan dari komunikasi dan komentar. Apakah dapat ditemukan solusi untuk hal tersebut?, hal tersebut akan dapat ditemukan jawabannya, karena sebenarnya jika kedua belah pihak dapat saling membuka dirinya dan mengemukakannya dengan sopan, biasanya dan kebanyakannya seharusnya tidak menjadi masalah di kemudian hari. Apa definisi komentar itu?, komentar adalah bagaimana cara kita mengekspresikan pendapat kita. Ini adalah definisi yang sangat sederhana tetapi kita harus dapat melihat satu kata yang penting, yaitu "Ekspresi", kata inilah yang menjadi masalah utama. Ekspresi yang terkadang berlebihan, ekspresi yang terkadang hanya berfokus pada masalah tersebut, ekspresi yang hanya berfokus pada faktor-faktor kebencian yang tidak beralasan, ekspresi yang berfokus pada hal-hal negatif dan tidak membangun diri sendiri dan orang lain, semua hal-hal itu tidak akan menjadi lebih baik, tetapi akan terus menerus semakin rusak. Tetapi atas semua itu, apakah ada solusi yang bisa diterapkan? Ada!, selalu ada solusi. Apakah solusinya?, solusinya adalah mengubah cara berkomentar terhadap sesuatu, mengubah cara dalam mengeluarkan sebuah statement dan ekspresi tersebut. apakah hal tersebut dimungkinkan? Hal tersebut dapat dilakukan, jika aturannya jelas dan tidak berbelat-belit. Dan produk dari aturan tersebut bersifat untuk kepentingan bersama, bukan kelompok tertentu. Maka hal tersebut dapat digambarkan dengan kerangka sebagai berikut:

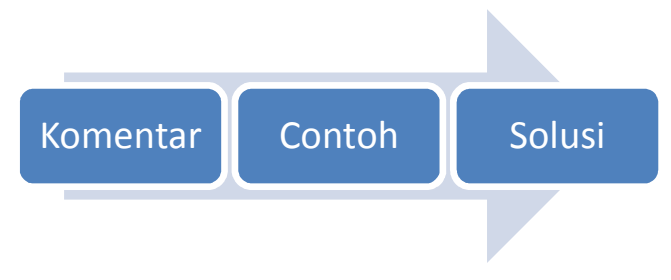

Gambar 9. Kerangka Komentar-Contoh-Solusi

Apa maksud kerangka di atas?. [25]; [26]; [27]. Kerangka di atas menggambarkan bahwa kebanyakan komentar terkadang/ sering mengeluarkan sebuah statemen tanpa memiliki arti apapun atau hanya berupa sebuah kalimat atau kata-kata tetapi tidak mengandung penjelasan yang dapat memberikan solusi. Dalam jurnal ini, tidak difokuskan pada hal-hal yang mengkritik, tetapi hanya memberikan sebuah usulan, hipotesis dan penilaian yang bersifat sementara, jika memungkinkan kerangka ini dapat diterapkan ke dalam cara berkomunikasi sehari-hari lewat sosial media. Maka, hal tersebut dapat digambarkan oleh kerangka sebagai berikut:

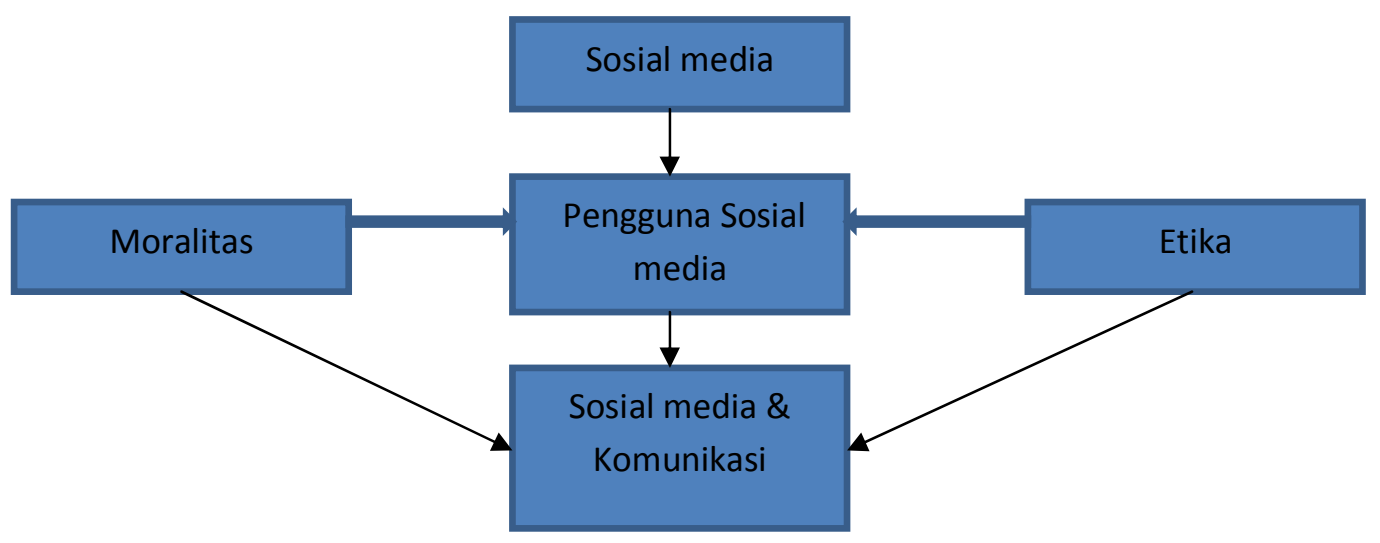

Gambar 10. Hubungan Antara Sosial media-Moralitas-Etika-Komunikasi 
Jadi, di sini timbullah pertanyaan: Bagaimana cara menjadi bijaksana dalam berkomunikasi terutama di dalam sosial media?. Pada pembahasan akan dibahas lebih details untuk hal tersebut.

\section{HASIL DAN PEMBAHASAN}

\section{Bagaimana Menjadi Netizen Yang Bijaksana Dalam Sosial Media}

Sebelum menjelaskan bagian ini, ada baiknya jika kita memahami apa arti sesungguhnya dari kata "Bijaksana", dalam Cambridge Dictionary, Bijaksana diartikan [16]:

a. Memiliki atau menunjukkan kemampuan untuk membuat penilaian yang baik, berdasarkan pemahaman yang mendalam dan pengalaman hidup

b. Memahami situasi yang tidak jujur atau cara melakukan sesuatu

Dari kata "Bijaksana" inilah maka terciptalah Kerangka yang dinamakan: "Netizen Development Methodology". Kerangka ini memiliki fungsi sebagai berikut: [32];[33];[34];[35]

- Menjadikan lebih bijaksana dalam berkomunikasi, tidak hanya melontarkan hoax, kata-kata yang tidak memiliki arti apapun, dan tidak memiliki makna untuk masa depan.

- Memberikan contoh dan solusi yang berguna baik untuk diri sendiri dan terutama masa depan orang lain dan/atau sebuah organisasi, insitutusi, perusahaan dan lainnya

- Mengembangkan solusi kreatif dan pengetahuan umum agar dapat berkomunikasi secara efesien dan efektif

- Memberikan pengetahuan yang luas terhadap masyarakat dan diri kita sendiri

- Menjadi seorang Netizen yang memiliki kualitas tinggi baik dalam hal sikap, etika dan moralitas

- Memiliki empati dan simpati yang dapat meningkatkan suatu hubungan menjadi lebih baik

- Memberikan solusi dan solusi sampai ditemukan jalan tengah untuk mengatasinya

Oleh sebab itu dapat dikatakan: "To become a wise netizen, firstly, you must know yourself, then you will understand others, and to be become a great netizen, you have to have an empathy when you say something, solution not only critics".

Netizen Development Methodology, ini adalah versi 1.0 yang membutuhkan pengembangan lebih lanjut, metodologi ini mungkin dapat digunakan di dalam beberapa kasus atau tinggal anda menggunakannya sesuai dengan kebutuhan yang anda perlukan. Dalam Netizen Development Methodology ini, akan dibatasi terlebih dahulu, dengan mengangkat kasus-kasus yang tidak berat, tetapi mungkin boleh dikatakan kasus-kasus tingkat ringan dan tingkat menengah, kasus-kasus berat seperti pelecehan, kata-kata yang tidak senonoh, tentunya sudah dapat dijerat dengan Undang-Undang ITE, dan juga oleh Hukum. Di sini tidak bermaksud mengubah apa yang sudah ada, tetapi memberikan ide, dan apa yang diciptakan dapat memberikan agar segala sesuatunya menjadi lebih baik, setuju dan tidak setuju adalah merupakan hak setiap orang yang perlu dihargai, belajar saling menghargai dan memberikan pendapat dengan santun, menghormati dan menghargai, karena di situlah letak komunikasi yang sesungguhnya. Lebih jauh lagi, hal ini dapat mendewasakan kita agar kita dapat berkomunikasi dengan sangat baik, yang disebut sebagai empathy communication dan hasil akhirnya adalah sebuah hubungan akan menjadi sangat baik satu sama lain, dalam kasus tertentu kita dapat melakukan Hard communication (hanya jika terpaksa dan ingin memperbaikki dengan urgency). Tetapi pada dasarnya komunikasi yang baik, sopan, terarah 
dan memberikan solusi akan dapat jauh lebih baik walaupun pada saat-saat tertentu diperlukan katakata keras, ini merupakan dasar kebudayaan komunikasi di Indonesia dan hal ini sangat perlu untuk diterapkan pada saat berkomunikasi di sosial media. [1];[2];[18];[19]

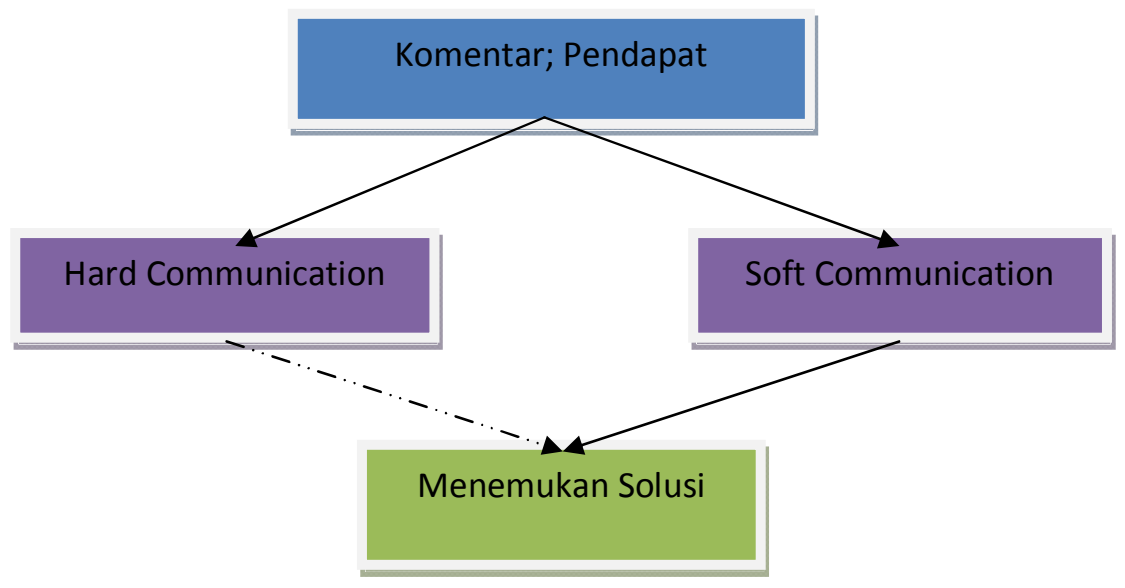

Gambar 11. Proses Komentar Dan Komunikasi

Pada gambar 11, dapat dilihat bahwa terdapat dua pilihan yang sangat penting pada saat memberikan komentar, hal ini akan dapat mempengaruhi proses menemukan solusi pada konteks dan konten informasi. Dari gambar di atas dapat dilihat terdapat dua hal penting yaitu: komunikasi keras (atau dengan bahasa yang lebih sopan: komunikasi yang tegas) dan komunikasi lunak (sopan dan baik), itu merupakan 2 pilihan yang seharusnya dipikirkan terlebih dahulu, mengapa terdapat garis putus-putus pada bagian komunikasi yang tegas?, karena pada bagian ini komukasi walaupun tujuannya adalah untuk menegaskan sesuatu terkadang seseorang dapat menangkap dengan persepsi lain, adalah lebih baik jika pada bagian komunikasi yang bersifat tegas, diberikan kombinasi dengan motivasi, nasehat dan solusi untuk dapat mengurangi kadar komunikasi yang dapat memicu kegaduhan di masyarakat, komunikasi adalah bagaimana kita bertutur kata dengan baik dan sopan, dimana pembaca yang melihat komentar dapat memperoleh manfaat dalam berinteraksi dan mendapatkan hal-hal positif.[7];[8];[9];[10]. Sebuah masukkan tanpa inteksi dua arah akan mengakibatkan kesalahpahaman besar, terkadang memang hal itu sulit untuk dilakukan jika kita tidak mengenal secara langsung orang yang menulis komentar tersebut, itulah salah satu kelemahan dalam sosial media, interaksi berkurang, hanya melalui dunia maya, dan ini tidak dapat dihentikan sampai ada aturan yang dapat menaungi hal tersebut.[36];[37]

Oleh sebab itu, dari penjelasan mengenai 2 cara berkomunikasi tersebut dengan menggunakan sosial media, maka dihasilkan sebuah kerangka atau metodologi untuk mengatasinya. Di bawah ini adalah Netizen Development Methodolgy yang diciptakan untuk memberikan arahan positif kepada para pengguna social media: 

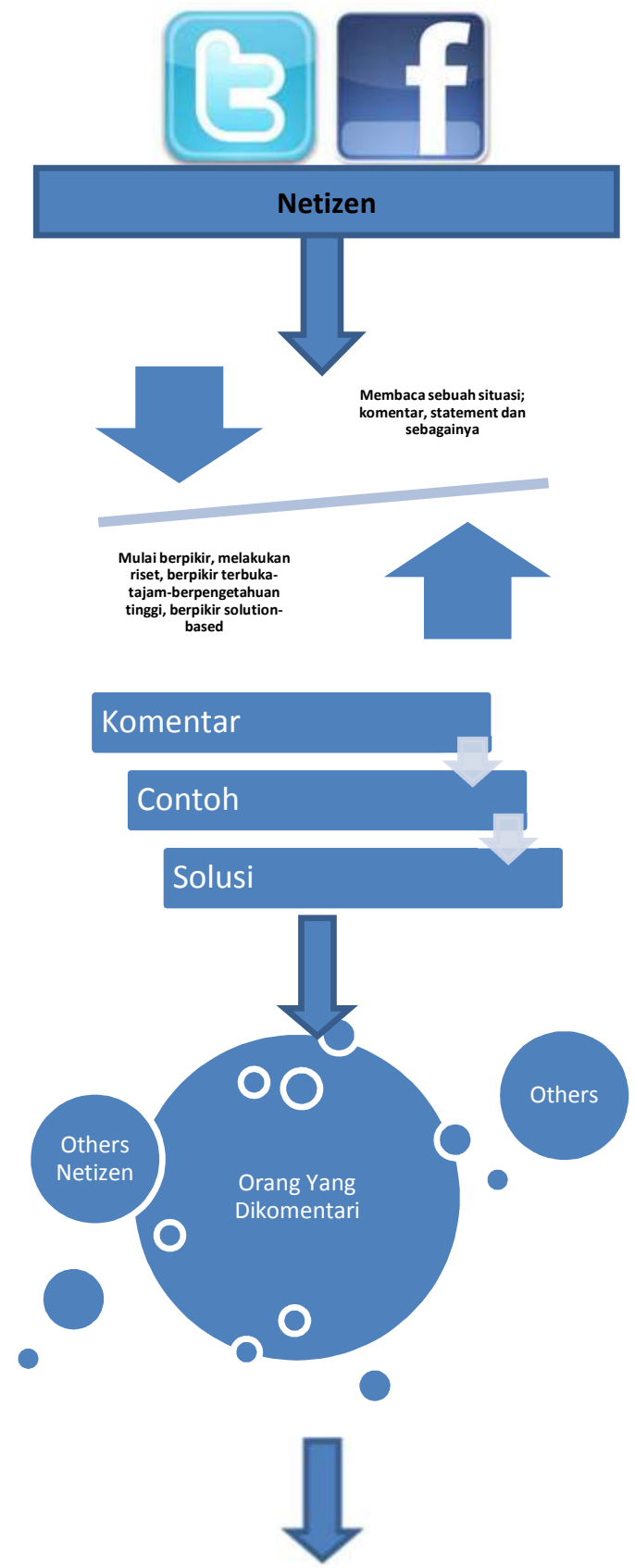

\section{Solusi Bersama-Sama [Positif/Negatif]}

Gambar 12. Netizen Development Methodology 
Dalam jurnal ini kami hanya mengambil 2 buah sosial media yang paling sering digunakan, yaitu Facebook dan Twitter. Ke dua sosial media ini ada perbedaannya, tetapi pembahasan perbedaan antara keduanya tidak akan dibahas di sini, pada jurnal ini akan dibahas tentang bagaimana menggunakan kerangka "Netizen Development Methodology" untuk menghasilkan solusi bersama baik positif dan negative. Prosesnya adalah sebagai berikut:

Pertama-tama, kita mengambil 2 sosial media sebagai contoh, seperti Facebook dan Twitter, sebagai contoh panduan

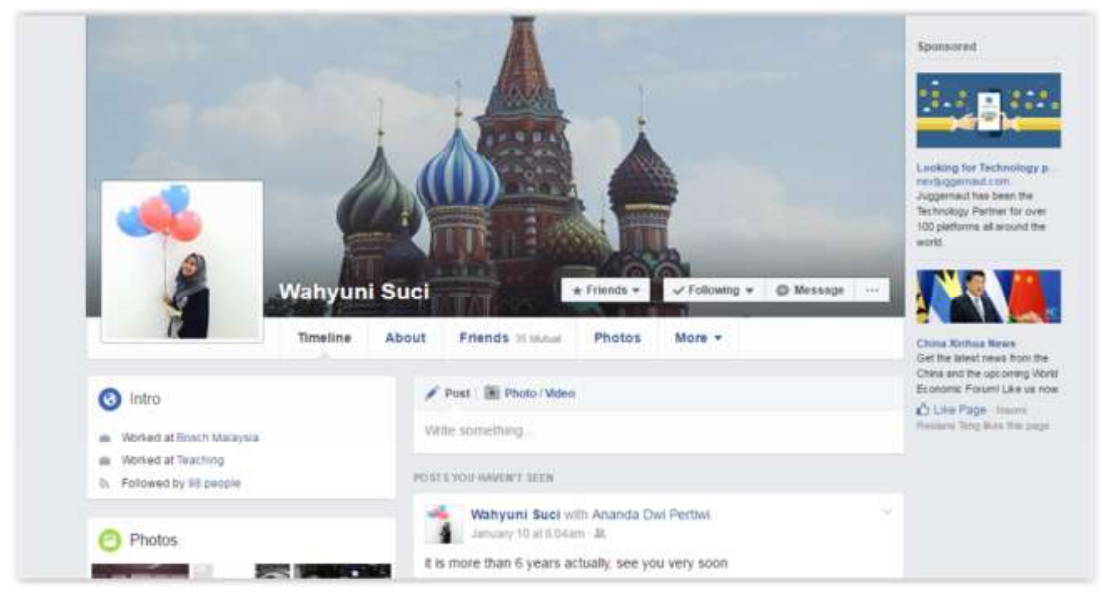

Gambar 13. Facebook

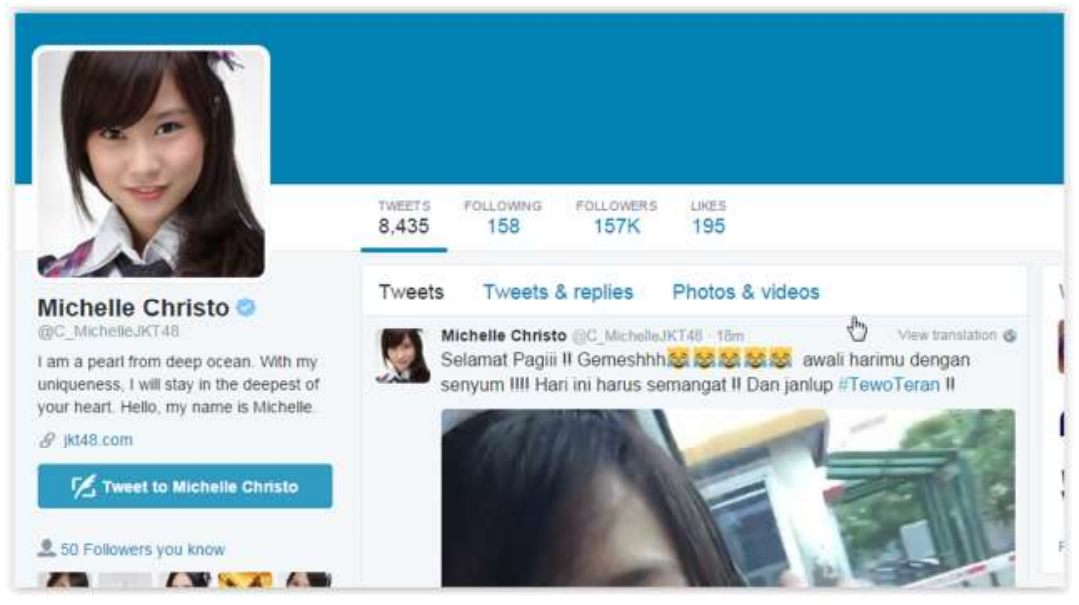

Gambar 14. Twitter

Dapat dilihat di dalam Facebook dan Twitter, terdapat 2 tempat untuk memberikan komentar, menulis status dan sebagainya, ini adalah merupakan tahap pertama di dalam sosial media, kita menyebutnya sebagai "pengguna aktif". Sosial media lainnya seperti Youtube dll. Dapat kita lihat di www.youtube.com, dan di dalam YouTube memiliki tempat untuk memberikan komentar 


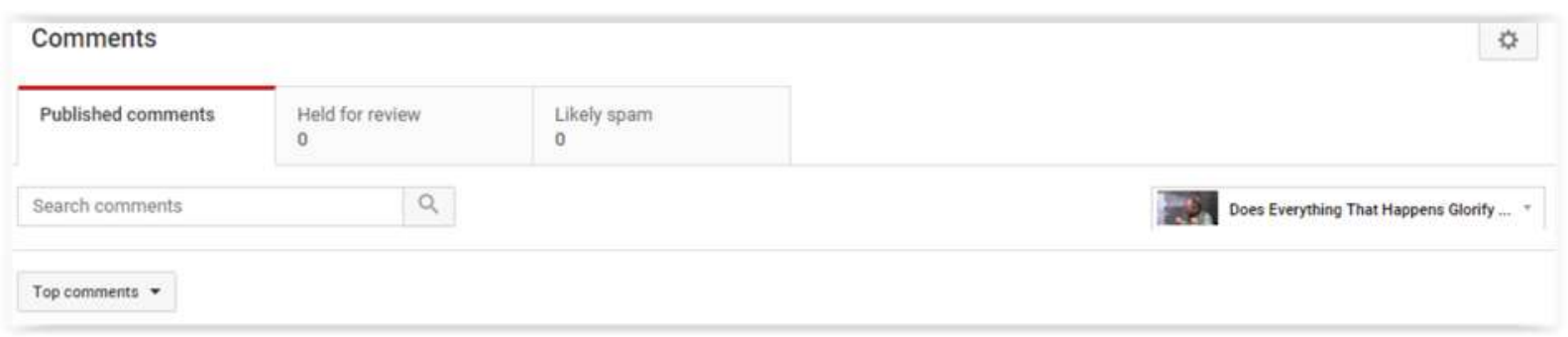

Gambar 15. Youtube - Comment

Sebagai seorang Wise Netizen, harus dapat dipahami bahwa penggunaan sosial media memiliki tujuan untuk memberikan komentar-komentar yang positif, dan fungsi utama dari sosial media adalah memberikan solusi-solusi positif dan bukan hoax ataupun hal-hal negatif lainnya yang dapat merusak kehidupan orang lain. Di sinilah tantangan berikutnya:

Kedua, di sini terdapat 3 tahap yang sangat penting- "Komentar-Contoh-Solusi". Seorang wise Netizen memiliki kemampuan research yang tajam dan pengetahuan yang luas, tidak hanya sekedar memberikan komentarnya tetapi tidak memiliki makna apapun di dalamnya. Sebagai contoh:

Pada saat memberikan komentar pada sebuah kejadian, berikan contoh-contoh yang terjadi pada Negara dan/atau kota dan/atau tempat-tempat lain yang memiliki kejadian yang sama, di samping itu memberikan solusi. Bahkan solusipun dibagi menjadi 3 hal, yaitu: [23];[24];[25];[26]

1. Solusi yang memiliki muatan sebagai contoh yang sudah terjadi

2. Solusi yang hanya memiliki muatan pendapat pribadi (pada bagian ini, harus berhati-hati agar tidak hanya mengeluarkan sebuah statement yang bernada kasar, menyerang, dan juga seakanakan mengetahui segala hal)

3. Jika tidak menyetujui sebuah informasi, maka solusi apa yang dapat diberikan? (Hal-hal positif apa yang bisa menjadi masukkan?)

Contoh lainnya: Jika kita melihat sampah berserakan di sebuah sungai dan tanpa tindakan apapun yang dilakukan untuk membersihkannya dan terdapat orang yang melakukan complain di sosial media, dapat juga memberikan komentar, tetapi harus memberikan contoh bagaimana cara membersihkan sampah di tempat-tempat lain, yang sudah pernah dilakukan, sehingga ini menjadikan sebuah masukan positif agar orang-orang dapat melakukannya. Contoh lainnya, mengenai "Status seseorang", di sini harus menjadi lebih bijaksana, dengan tidak hanya mengomentari secara spontan apa yang menjadi statusnya, kecuali dalam hal-hal tertentu dapat dilakukan komentar secara tegas (tetapi inipun hanya boleh dilakukan, jika sudah di luar batas, dengan memperhatikan batasan hukum, etika dan moral yang ada), dalam mengomentari status, beberapa hal harus kita perhatikan:

1. Apakah kita mengenal orang tersebut?

2. Apa kegunaannya jika memberikan komentar terhadap orang tersebut?

3. Apa yang kira-kira dibutuhkan orang tersebut, pada saat memberikan komentar untuk orang tersebut sehingga orang tersebutpun dapat memperbaikki dirinya? 
4. Mengapa hal tersebut sangat diperlukan, yaitu untuk memberikan komentar terhadap orang tersebut?

5. Apa efek samping dari komentar terhadap orang tersebut?

6. Contoh-contoh apakah yang dapat diberikan sebagai masukkan kepada orang tersebut, agar kehidupannya menjadi lebih baik? (ini berlaku jika status terkesan negatif, menurut sudut pandang subjektif, tetapi jika sudah positif, maka perlu memberikan kalimat penguat agar menjadi lebih positif lagi)

7. Apa solusi yang dapat diberikan kepada orang tersebut?

Mungkin ini berkesan, sepertinya "Kok rumit sekali, mau menulis saja, dibuat ribet". Hal ini tidak bermaksud untuk membatasi kebebasan di dalam berbicara, memberikan komentar dan sebagainya, tetapi pemahamannya adalah hanya mengatakan, bahwa dalam beberapa kasus dan situasi sebagai seorang Wise Netizen hendaknya memberikan komentar yang memiliki kualitas tinggi sehingga akan dapat memberikan kontribusi yang positif terhadap kehidupan orang lain, dapat diatakan "Amal Comment For Heaven, Someday". Di sini juga perlu mempertimbangkannya dengan sangat cermat, dimana dalam segala hal yang dilakukan terus-menerus memberikan kontribusi negatif untuk kehidupan ini.

Ketiga, yang terakhir, Mengapa di sini terdapat solusi positif dan negatif?. Hal ini dapat dikatakan sebagai "keseimbangan".[27];[28];[29];[30]. Sebagai contoh, pada saat solusi positif diberikan, maka dalam beberapa hal tidak lepas juga dari hal-hal sebaliknya, mungkin ada hal-hal negatif yang dilontarkan secara tidak sengaja (Setiap orang memiliki gaya komunikasi masingmasing, yang perlu pengamatan lebih dalam). Sederhanya, "ini adalah solusi dari saya, tetapi kalau negatifnya seperti ini, kira-kira". Memberikan keseimbangan di dalam komentar, atau mungkin bahkan dalam memberikan contoh, jadi tidak terkesan untuk memberikan "brain wash" agar semuanya terkesan baik-baik saja. Contoh yang lebih jauh lagi, missal di sebuah tempat terdapat sampah, ini solusi di Negara lain dalam mengelola sampah, tetapi ini efek negatifnya jika sampah tersebut tidak dikelola dengan baik, ini cara Pemerintah Negara A dalam mengatasi banjir dan solusinya adalah seperti ini, tetapi ini efek negatifnya jika kita tidak mengatasi banjir Demikian, penerapan dari Netizen Development Methodology

\section{KESIMPULAN}

Pada bagian akhir ini, kami akan memberikan kesimpulan dan saran untuk menghadapi Masyarakat Ekonomi Asean (MEA) dan/atau Globalisasi sebagai berikut:

\section{IV.I. Kesimpulan}

- Dalam menghadapi MEA dan Globalisasi harus memperhatikan beberapa hal penting, diantaranya adalah sikap, mental dan sebagainya yang dapat menunjang peningkatan kedewasaan, dimana sosial media dapat digunakan sebagai salah satu pilar untuk memajukan sebuah bangsa

- Penggunaan sosial media harus dapat digunakan dalam memberikan kontribusi positif bagi kehidupan orang lain, bagi sebuah situasi dan kondisi dan bagai banyak hal dalam kehidupan agar dapat tercipta kehidupan yang baik di dalam masyarakat dan dunia 
- Netizen Development Methodology, merupakan salah satu framework yang diciptakan bagi para pengguna internet, yang mungkin dapat digunakan untuk membantu memberikan solusi dan sebagainya.

\section{V.SARAN}

- Netizen Development Methodology ini perlu dikembangkan lagi menjadi sebuah metodologi yang dapat memberikan kontribusi positif dan mungkin dapat digunakan oleh seluruh dunia dalam memberikan komentarnya

- Dalam berpendapat atau memberikan sebuah statement, harus memiliki dasar yang kuat seperti: memiliki pengetahuan yang luas, ketajaman dalam berpikir, sikap, etika dan moralitas serta memiliki batasan-batasan hukum (memiliki pengetahuan tentang hukum secara umum)

- Perlu disosialisasikan dengan lebih luas tentang bagaimana sebuah Undang-undang dapat menjerat seseorang bila memberikan statement yang 93egative, dan apa saja batasanbatasan yang perlu diperhatikan, dapat dijelaskan di website secara lebih mendetails.

\section{DAFTAR PUSTAKA}

[1] Femi Richard Omotoyinbo, Online Radicalisation: The Net Or The Netizen?, 2014, 4(1), p.51-61, Socialines Technologijos/Social Technologies

[2] Guadalupe Correa-Cabrera; Maria Fernando Machuca \& Ruth Ann Ragland, Citizen Journalism: From Thomas In Boston To Twitter Tamaulipas A Case Study, The Journal Of Social Media In Society, 5(3), P.283

[3] Hauben, Michael; Hauben, Ronda (November 1995). "What is a Netizen?". Access Date: 8 July 2015.

[4] Hauben, Michael F. (24 November 1995). "The Netizens and Community Networks Presented at the Hypernetwork '95 Beppu Bay Conference". Access Date: 6 June 2015.

[5] Hauben, Michael. "The Expanding Commonwealth of Learning: Printing and the Net". columbia.edu. Retrieved 5 June 2015.

[6] DeLoach, Amelia (September 1996). "What Does it Mean to be a Netizen?". Access Date: 6 June 2015.

[7] DeLoach, Amelia (September 1996). "What is a Netizen?". Access Date: 6 June 2015.

[8] Judith Balea (2016), The latest stats in web and mobile in Indonesia (INFOGRAPHIC), https://www.techinasia.com/indonesia-web-mobile-statistics-we-are-social

[9] Sophie Loras (2016), Social media in Indonesia: big numbers with plenty of room to grow, https://www.clickz.com/social-media-in-indonesia-big-numbers-with-plenty-of-room-togrow/94062/

[10] http://nasional.kompas.com/read/2015/11/06/07423391/Pro.Kontra.Surat. Edaran. Hate. Speech. dan Jawaban Kapolri. Access Date: 6 November'2015; Time: 10:00 am

[11] Kathleen Chaykowski (2016), Facebook Messenger Reaches 800 Million Users, Plans For Boost In Chats With Businesses, http://www.forbes.com/sites/kathleenchaykowski/2016/01/07/facebook-messenger-reaches800-million-users-plans-for-boost-in-chats-with-businesses/\#2715e4857a0b1c9bd17712b1, Access Date: 9 January'2016 
[12] Kathleen Chaykowski (2016), Meet The Queen Of Imgur, The Image-Sharing Site That's Half The Size Of Twitter, http://www.forbes.com/sites/kathleenchaykowski/2016/01/08/meet-thequeen-of-imgur-the-image-sharing-site-thats-half-the-size-oftwitter/\#2715e4857a0b53da76c46cd0, Access Date: 9 January'2016

[13] Daniel Goleman (1999), Emotional Intelligence, Gramedia Pustaka Utama, Jakarta, Indonesia

[14] Daniel Goleman, (1999), Working With Emotional Interlligence, Gramedia Pustaka Utama, Jakarta, Indonesia

[15] Mark N. Abadiano, Dr. PhD; Dr. Amelia Bonotan, PhD \& Dr. Rossa V. Makiling, PhD, The Dynamics Of Netizen's Information-Sharing In Social Media: Why Do We Share Information In Social Media?, International Journal Of Interdiciplinary Research \& Innovations, Vol.2, Issue 3, PP: (30-55), Month: July 2014-September 2014

[16] Matt Schiavenza, "Enough with the word "Netizen"'", The Atlantic, 25 September 2013

[17] Michael Hauben, THE NET AND NETIZENS: The Impact the Net has on People's Lives, $\mathrm{http}: / /$ www.columbia.edu/ hauben/CS/netizen.txt

[18] http://dictionary.cambridge.org/dictionary/english/wise, Access Date: 23 December'2015

[19] "The need for a Netizens Association". March 1996. Access Date: 8 July 2015.

[20] The Net and Netizens by Michael Hauben, Columbia University.

[21] Wen Gong, Factors Influencing Perceptions Toward Social Networking Websites In China, Proceeding Cultural Attitudes Towards Technology And Communication, 2012, Murdoch University, Australia

[22] What is netizen? Definition; http://whatis.techtarget.com/definition/netizen; Access Date: 4 June'2015

[23] Brian Fung, "'Netizen': Why Is This Goofy-Sounding Word So Important in China?", The Atlantic, 11 October 2012

[24] Christer Asplund (2012), Beyond "Triple Helix" - towards "Quad Helix" http://blog.bearingconsulting.com/2012/03/22/beyond-triple-helix-towards-quad-helix/

[25] Ilya Pozin (2012), 7 Tips for Online Marketing on a Tight Budget, http://www.forbes.com/sites/ilyapozin/2012/06/29/7-tips-for-online-marketing-on-a-tightbudget/\#2715e4857a0b4ac2cc7a102e, Access Date: 21 December'2015

[26] John Rampton (2015), 10 SEO Tips For Marketing Your Startup in 2015, http://www.forbes.com/sites/johnrampton/2015/06/17/10-seo-tips-for-marketing-your-startupin-2015/\#2715e4857a0b58742bf34266, Access Date: 21 December'2015

[27] Drew Hendricks (2014), 8 Sosial media Advertising Tips To Boost Your ROI, http://www.forbes.com/sites/drewhendricks/2014/06/19/8-social-media-advertising-tips-toboost-your-roi/\#2715e4857a0b7ffd271232f9, Access Date: 20 December'2015

[28] Drew Hendricks (2014), 20 Sosial media Tips To Rule In 2014, http://www.forbes.com/sites/drewhendricks/2014/05/14/20-social-media-tips-to-rule-in2014/\#2715e4857a0b7755baf03fab, Access Date: 21 December'2015

[29] Dominic Gabriel Go (2013), Think before you retweet: Be better netizens during disasters

[30] Ernest J Wilson III (2012), How To Make A Region Innovative, Issue 66, Spring 2012, http://blog.bearing-consulting.com/2012/03/22/beyond-triple-helix-towards-quad-helix/

[31] Watch what you tweet, choose what you retweet, and you're already helping in your own little way, http://www.rappler.com/move-ph/issues/disasters/40019-social-media-disasters-netizens

[32] Yunjuan Luo, The Internet And Agenda Setting In China: The Influence Of Online Public Opinion On media Coverage And Government Policy, International Journal Of Communication, 8(2014)

[33] Kiran Bala Dr., Social Media And Changing Communication Patterns, Summer Issue, June 2014, Vol.5, No.1, Global Media Journal-Indian Edtion 
[34] Latitha Muniandy \& Balakrisnan Muniandy, PhD, The Impact Of Social And Political Aspects In Malaysia: An Overview, International Journal Of Humanities And Social Science, Vol 3, No.11, June 2013

[35] Netizen, Dictionary.com; Access Date: 6 June'2015

[36] Ronda Hauben (2012), Netizens and Communication: A new Paradigm, at a small celebration in honor of the 15th Anniversary of the publication of the print edition of the book Netizens

[37] Seese, Michael. Scrappy Information Security. p. 130. ISBN 978-1600051326. Retrieved 5 June 2015. 